\title{
La correction des épreuves erronées d'ARN
}

Le dogme selon lequel l'ARN messager est toujours fidèle - et neutre - dans la transmission de l'information génétique en provenance du noyau est maintenant battu en brèche dans de nombreux exemples. Nous avons déjà rapporté ici le cas de certains messagers mitochondriaux de kinétoplastes qui doivent subir un nombre considérable d'additions ou de délétions de résidus uridyliques pour être transformés en molécules traductibles [1] et celui de l'apolipoprotéine B dont le messager est modifié dans les cellules intestinales pour faire apparaître un codon stop prématuré: un acide cytidylique est, dans cet ARNm, transformé en acide uridylique, le codon glutamine CAA étant changé en UAA [2]. Une autre situation a été décrite dans le paramyxovirus de la rougeole dont un transcrit possède deux $G$ dont il n'existe pas d'équivalent dans le génome viral [3].

Une équipe française de Strasbourg [4] et une équipe canadienne d'Halifax en Nouvelle-Écosse [5] viennent d'enrichir cette liste d'une observation supplémentaire dans les mitochondries de plantes, en l'occurrence de blé. La présence, dans le génome mitochondrial, de codons CGG (arginine), là où la séquence protéique indique que, selon le code génétique universel, devraient se trouver des tryptophanes, avait suggéré que, comme cela est le cas pour d'autres génomes mitochondriaux, ces organites de plantes possédaient un code particulier. Cette explication était cependant en contradiction avec l'impossibilité dans laquelle-on se trouvait de mettre en évidence une espèce d'ARNt reconnaissant le codon CGG et chargé par un tryptophane. En réalité, les codons CGG des gènes mitochondriaux sont soit conservés dans les transcrits, et correspondent effectivement à des arginines, soit sont changés en UGG... le codon tryptophane universel. Le mécanisme de cette transition CGG $\rightarrow$ UGG n'est pas connu, mais il pourrait être similaire à celui de la modification CAA $\rightarrow$ UAA du messager de l'apolipoprotéine B dans l'intestin. Dans les deux cas, il est évident que le processus n'est pas aléatoire mais intéresse des codons très particuliers, les autres codons identiques n'étant pas modifiés (ou dans le cas des plantes, ne l'étant pas tous). Pour ce qui est du messager de l'apolipoprotéine B, des chercheurs californiens ont démontré que, pour subir la modification typique des cellules intestinales, le codon cible CAA devait être inclu dans un grand fragment de séquence codant pour la protéine : des gènes hybrides contenant le codon cible dans un fragment de $63 \mathrm{pb}$ dérivé de la séquence du gène de l'apolipoprotéine $B$ ne donnent, lorsqu'ils sont introduits dans des cellules intestinales en culture, que la forme non modifiée d'ARN ; en revanche, lorsque ces mêmes constructions contiennent $354 \mathrm{pb}$ dérivées de la séquence du gène étudié, elles donnent des transcrits modifiés dans les cellules intestinales et non modifiés dans les cellules non différenciées [6]. Le système modificateur reconnaît donc probablement une superstructure spécifique d'une séquence donnée. En principe, la modification $\mathrm{C} \rightarrow \mathrm{U}$ pourrait être, soit cotranscriptionnelle, due à une incorporation non canonique d'un nucléotide lors de la transcription, soit post-transcriptionnelle. Le mécanisme de ce second type de réaction - en fait le plus probable - pourrait être une désamination enzymatique de la cytosine du codon cible. Il existe des arguments pour penser que cette réaction survient très précocement dans le noyau, avant même l'étape de polyadénylation. En effet, la modification CAA - UAA est associée à l'utilisation d'un site de polyadénylation situé peu après le codon modifié alors que, en l'absence de modification, le site habituel est localisé 7 kilobases en aval (en 3') [6]

Ainsi ces exemples de "correction sur épreuve » des molécules d'ARN ajoutent-elles à l'impression de grande flexibilité de cet acide nucléique qui peut être message, enzyme, mais aussi substrat de modifications très spécifiques qui impliquent probablement la reconnaissance de structures particulières du brin d'ARN.

A.K.

1. Simpson L, Shaw J. RNA editing and the mitochondrial cryptogenes of kinetoplastid protozoa. Cell 1989; 57 : 355-66.

2. Powell LM, Wallis SC, Pease RJ Edwards YH, Knott TJ, Scott J. A novel form of tissue specific RNA processing produces apolipoprotein B48 in intestine. Cell 1987 $50: 831-40$.

3. Cattaneo R, Kaelin K, Bazko K, Billeter MA. Measle virus editing provides an additional cysteine-rich protein. Cell 1989; 56 . 759-64.

4. Guaberto JM, Lamattina L, Bonnard G, Weil JH, Grienenberger JM. RNA editing in wheat mitochondrial results in the conservation of protein sequences. Nature 1989; 341 660-2.

5. Covello PS, Gray MW. RNA editing in plant mitochondria. Nature $1989 ; 341: 662$

6. Boström K, Lauer SJ, Poksay KS, Garcia Z Taylor JM, Innerarity TL. Apolipoprotein B48 RNA editing in chimeric apolipoprotein EB mRNA. J Biol Chem 1989; 264: 15701 8. 